\title{
Complutum
}

ISSN: 1131-6993

\section{Las Zonas Arqueológicas en la legislación canaria de patrimonio cultural. Implicaciones para la gestión de su protección}

\author{
Diria Morales Casañas ${ }^{1}$ y Elena María Pérez González ${ }^{2}$
}

Recibido: 23/03/2021 / Aceptado: 04/08/2021

Resumen. En la actualidad, en las Islas Canarias se encuentran declarados 83 Bienes de Interés Cultural (BIC) con categoría de Zona Arqueológica (ZA). De ellos, 36 se encuentran en la isla de Gran Canaria, seguida por Tenerife con 27, Fuerteventura y La Palma con 5 zonas, el Hierro con 3, la Gomera con 2 y finalmente, Lanzarote con sólo una zona arqueológica. En este trabajo se reflejan algunas de las deficiencias en la gestión de este tipo de bienes, ocasionadas por el propio procedimiento de declaración, y que impiden una clara y fluida gestión del patrimonio arqueológico cuyo objetivo debería ser, a tenor de las más actuales tendencias en la gestión patrimonial, integrar, cohesionar y desarrollar social y económicamente los territorios. Para ello, se ha centrado el estudio en el análisis de la organización legal y administrativa en la gestión del patrimonio arqueológico, la política de autorizaciones de las intervenciones arqueológicas, la de protección reflejada en los BIC, la delimitación de áreas de protección y su conversión en parque arqueológico, lo que nos han ayudado a profundizar y mostrar el estado actual de los bienes arqueológicos canarios y avanzar en la evaluación y diagnóstico de la gestión del patrimonio arqueológico.

Palabras clave: patrimonio arqueológico, ley, parques arqueológicos, Islas Canarias

\section{[en] Archaeological areas in the Canarian legislation on cultural heritage. Implications for the management of their protection}

\begin{abstract}
There are currently 83 declared Assets of Cultural Interest (BIC) with the category of Archaeological Zone (ZA) in the Canary Islands. Of these, 36 are on the island of Gran Canaria, followed by Tenerife with 27, Fuerteventura and La Palma with 5 zones, El Hierro with 3, La Gomera with 2 and finally, Lanzarote with only one archaeological zone. This work reflects some of the deficiencies in the management of this type of property, caused by the declaration procedure itself, and which prevent a clear and fluid management of archaeological heritage, the aim of which should be, according to the most current trends in heritage management, to integrate, cohere and develop the territories socially and economically. To this end, the study has focused on the analysis of the legal and administrative organisation in the management of archaeological heritage, the policy of authorisations for archaeological interventions, the protection reflected in the BICs, the delimitation of protection areas and their conversion into archaeological parks, which have helped us to study in depth and show the current state of Canarian archaeological assets and to make progress in the evaluation and diagnosis of the management of archaeological heritage.
\end{abstract}

Keywords: archaeological heritage, law, archaeological parks, Canary Islands.

Sumario. 1. Introducción. 2. Objetivos y metodología. 3. El marco normativo para la gestión del patrimonio arqueológico en las Islas Canarias: muerte entre la abundancia. 3.1. La Ley de Patrimonio Histórico de Canarias (1999). 3.2. La Ley de Patrimonio Cultural de Canarias (2019). 4. Los efectos de ser-o sufrir ser- BIC. 4.1. Entonces, ¿parques arqueológicos en las Islas Canarias? 5. Conclusiones. Bibliografía. Anexo normativo.

Como citar: Morales Casañas, D.; Pérez González, E. M. (2021): Las Zonas Arqueológicas en la legislación canaria de patrimonio cultural. Implicaciones para la gestión de su protección. Complutum, 32(2): 309-323.

\footnotetext{
Universidad de La Laguna.

E-mail: dmoralec@ull.edu.es

2 Universidad Europea de Canarias.

E-mail: elenamaria.perez@universidadeuropea.es
} 


\section{Introducción}

Prácticamente todo lo que tiene que ver con la arqueología genera una fascinación romántica en la sociedad, a excepción de lo relacionado con su gestión, sobre la que poco o nada trasciende, salvo la idea de constituir un extraño "cajón de sastre" en el que cohabitan normas, administraciones, planes, proyectos, autorizaciones o presupuestos, entre otras cuestiones. A pesar de ello, las instituciones públicas y privadas se han comprometido en su conservación, promulgando normas y diseñando proyectos patrimoniales, los cuales, sin embargo, no han estado exentos de críticas, y registrando frecuentes y fallidos intentos en la conservación de los bienes arqueológicos, tal es el caso de la supuesta protección que dota el ser zona arqueológica declarada Bien de Interés Cultural (en adelante BIC).

Muchas comunidades autónomas a lo largo de las últimas décadas han evaluado sus propios modelos de gestión, con el fin de adecuar sus políticas a los nuevos contextos socioeconómicos. Reflejo de ello son las modificaciones realizadas en varias leyes de patrimonio aprobadas en la década de los 90 del siglo pasado, como es el caso de la propia normativa canaria que, en 1999 aprobó su la Ley de Patrimonio Histórico ${ }^{3}$ (en adelante LPHC) y en el año 2019 aprobó la Ley de Patrimonio Cultu$\mathrm{ral}^{4}$ (en adelante LPCC).

La Comunidad Autónoma de Canarias activó las primeras propuestas de organización de su patrimonio arqueológico a mediados de los años 80 del siglo pasado, una vez que le fueron transferidas las competencias en esta materia desde el Estado Central. Inmediatamente, comenzó a autorizar intervenciones con el fin de conservar y conocer estos bienes. Con el tiempo, la finalidad o motivación de las intervenciones y actuaciones sobre el patrimonio arqueológico ha ido cambiando, así como nuestro contexto social y económico, que ha determinado el uso y gestión del patrimonio arqueológico. Desequilibrios que hoy en día se siguen reflejando, en la gestión que cada isla hace de su patrimonio arqueológico.

Los análisis realizados en torno al impacto de la gestión del patrimonio arqueológico

Ley 4/1999, de 15 de marzo, de Patrimonio Histórico de Canarias (B.O.C. $n^{\circ} 36$ de 24.3.99).

4 Ley 11/2019, de 25 de abril, de Patrimonio Cultural de Canarias (B.O.C. $n^{\circ} 90$ de 13.5.19). en las Islas Canarias han sido escasos. Así, en 1995, se publicó el primer trabajo que evaluó las actuaciones institucionales más destacadas en materia de patrimonio arqueológico, desde la asunción de las competencias transferidas hasta 1992 (Jiménez 1995). En particular, el autor analizó los datos administrativos de los bienes arqueológicos declarados BIC o que estaban en proceso, unos indicadores que clasificó como incoaciones BIC, declaraciones, información pública, incoación de la delimitación, vista de los interesados y cerramientos de las zonas arqueológicas (Jiménez 1995: 23). En su análisis, el autor identificó grandes desequilibrios insulares motivados por la descoordinación coyuntural entre las diversas instancias institucionales y prioridades de actuación (Jiménez 1995: 29).

No será hasta los primeros años del siglo XXI, cuando se difundan más trabajos críticos sobre la gestión del patrimonio arqueológico canario, en particular los referidos a la Ley de Patrimonio Histórico de Canarias y su desarrollo. En ellos se incluyen aspectos institucionales y administrativos que han influido en su implementación, así como los estudios sobre el primitivo poblamiento humano de las islas -centrados en la etapa franquista- y que también consideraron diversos aspectos de la gestión en ese periodo (p. ej. Clavijo y Navarro 2004, 2005; del Arco Aguilar y Farrujia de la Rosa 2004; Farrujia de la Rosa 2006). Durante las Jornadas de Patrimonio Histórico celebradas en Lanzarote en el año $2005^{5}$ se presentaron varios análisis orientados a valorar la gestión patrimonial de los bienes arqueológicos durante las últimas décadas, en todos sus ámbitos de actuación. En el marco de los trabajos presentados en esta reunión, destacan los realizados por Navarro, Tejera y Cuenca (2005), así como por Jiménez (2005). En el primer caso, el análisis se centró en la descripción de la política desarrollada por la Administración Autónoma, por períodos legislativos durante las dos últimas décadas. En el segundo caso, se analizó la actuación de la Comisaría de Patrimonio Arqueológico y Etnográfico entre los años 1982 y 1992 (Jiménez 2005), retomando algunos de los aspectos planteados en

\footnotetext{
V Jornadas de Patrimonio Histórico. La Arqueología canaria: Análisis de partida. Celebradas en Arrecife de Lanzarote el 16,17 y 18 de marzo de 2005. Un resumen de las mismas puede consultarse en http://www.cabildodelanzarote.com/patrimonio/VIcongreso/conclusionesV.asp [Fecha último acceso 17/03/2021].
} 
el año 1995, sobre la política de declaración de Bienes de Interés Cultural (Jiménez 1995). Otros autores se centraron en las relaciones y realidades de la arqueología empresarial, la administración, la investigación arqueológica y el patrimonio que, sin duda, determinaron la percepción y el modo de entender la gestión de la Arqueología canaria en ese momento (Barroso y Marrero 2005; Moreno et al. 2005; Pérez y Soler 2005; Velasco y Rodríguez 2005). En el año 2013, se presentó la tesis doctoral denominada Diagnosis y propuestas para una gestión del patrimonio arqueológico de las Islas Canarias (Pérez 2015), en la que se realizó un estudio de las intervenciones arqueológicas realizadas en el Archipiélago desde los años 80 del siglo pasado, hasta el año 2011, abarcando así un periodo en el que se desarrollaron 7 legislaturas del gobierno autonómico, administración con competencias en la autorización de las intervenciones arqueológicas hasta el día de hoy. En esta investigación, la autora puso de manifiesto, entre otros aspectos, la ausencia de una política planificadora por parte de las administraciones con competencias en gestión del patrimonio arqueológico además de la inexistencia de coordinación entre ellas. Ello, según la autora, ha determinado la existencia de otros escenarios y motivaciones en los que se ha desenvuelto la política de autorizaciones de las intervenciones arqueológicas como han sido los acontecimientos políticos e institucionales o los cambios socioeconómicos impulsados por el turismo y donde se resalta, además, que la política proteccionista de los bienes arqueológicos se ha basado en la declaración de BIC en los que, en su mayoría, no se cumplen los preceptos básicos recogidos en las normas como es su conservación, mantenimiento y difusión, sobre todo en lo que respecta a la creación de parques arqueológicos.

Son precisamente las publicaciones en torno al papel del patrimonio arqueológico en el turismo, las que han puesto de manifiesto la degradación y el no uso y gestión de muchos yacimientos arqueológicos, principalmente de los BIC declarados como Zonas Arqueológicas (en adelante ZA), como recursos turísticos y de ocio potenciales (Pérez y Chávez 2010). En estos estudios, se evidencia que, aun existiendo numerosos sitios protegidos con la categoría de BIC, la mayoría no se han puesto en valor, ni activado para su visita $-\mathrm{o}$ cualquier otro tipo de uso social-.
El Plan de Desarrollo de Canarias 20002006 (PDCAN) (Gobierno de Canarias 2000), en el cual se incluyó un programa de Conservación y Rehabilitación del Patrimonio Histórico, Artístico y Cultural, tenía como fin conseguir el "mantenimiento, rehabilitación y difusión del Patrimonio Histórico y Cultural de las islas", junto al objetivo, además de desarrollar la identidad local y regional de la Comunidad, y potenciar el turismo a través de la utilización de este tipo de patrimonio (Gobierno de Canarias 2000: 170). Ante estas intenciones, sería lógico esperar la existencia de un número más elevado de actuaciones sobre el patrimonio arqueológico orientadas el ocio y el turismo. Algo que, además, no nos debería extrañar al ser el turismo la principal actividad económica de las Islas Canarias y porque las convocatorias de la Administración Autonómica iniciadas en 1993 - subvenciones genéricas - para realizar estudios sobre el patrimonio histórico, en general, y el arqueológico en particular, tenían como una de las líneas prioritarias el turismo. La realidad no ha sido así. Lo cierto es que el patrimonio arqueológico en las Islas Canarias ha sido poco o nada considerado como atractivo de ocio y turismo; su papel ha estado formulado dentro de la construcción de la identidad canaria con acciones dentro de las intenciones políticas y también supeditado a las obras y planeamiento urbano. Estos discursos, se han realizado, además, al margen de la investigación, con claras diferencias no solo entre la política autonómica y las de las diferentes islas, sino, también, entre ellas (Pérez et al. 2015).

\section{Objetivos y metodología}

El objetivo de este trabajo es reflexionar sobre la protección real del patrimonio arqueológico, en particular del patrimonio de las Islas Canarias y contribuir, así, al conocimiento de la investigación en la gestión de este tipo de bienes. Se buscan alternativas acordes a los contextos actuales, contextos llenos de retos, donde el turismo, la participación ciudadana y, en general, los conflictos de diversa naturaleza o el uso de nuevas estrategias interpretativas del patrimonio, están siendo poco consideradas en esta comunidad y, por tanto, se sitúan al margen del desarrollo sostenible del Archipiélago.

Para ello, este trabajo se aborda a partir del análisis documental. Se realiza una revisión 
de la bibliografía académica y científica sobre el objeto de estudio, se ha analizado la información disponible sobre los BIC en el Boletín Oficial de Canarias (BOC), en el Boletín Oficial del Estado (BOE), así como los expedientes originarios y de autorización de intervención arqueológica de la Dirección General de Patrimonio Cultural de Canarias, así como los propios expedientes BIC, de la misma institución.

Se busca generar una reflexión sobre los efectos de la normativa de protección del patrimonio arqueológico y de su entorno - centrados en los BIC-, y sobre las consecuencias de su aplicación, en un intento de aspirar a una gestión más integral y sostenible de los bienes arqueológicos de las Islas Canarias.

Este análisis es complejo de partida, ya que dentro de las zonas protegidas hay que diferenciar aquellas que ya lo están por ministerio, de las diversas leyes estatales y autonómicas dedicadas a regular el patrimonio histórico o cultural (Ley 16/1985 de 25 de junio, de Patrimonio Histórico Español, Ley 4/1999 de 15 de marzo, de Patrimonio Histórico de Canarias o la Ley 11/2019 de Patrimonio Cultural de Canarias), de aquellas ZA que lo son por declaración administrativa desde sus inicios al no contar entre su delimitación con grabados rupestres ${ }^{6}$. Para el primer conjunto, las declaradas por ministerio, el mayor problema reside en la ausencia en muchos casos de las delimitaciones de los yacimientos, bien porque algunos casos nunca se inició su delimitación o porque no se concluyó el procedimiento administrativo de declaración (por transferencia de funciones entre administraciones públicas, dejadez o por aparición de nuevas circunstancias que hicieron que se provocase su caducidad). En todo caso han quedado desprotegidas amplias zonas con posibles restos relacionados con los yacimientos centrales.

La aportación de este trabajo, por tanto, está orientado a profundizar y valorar la eficacia y eficiencia de las protecciones BIC y de la delimitación de su entorno de protección. Se parte de la hipótesis de que tal y como están planteados en la normativa, los aspectos relacionados con la gestión y el uso de las ZA, determinan bloqueos importantes para la activación social y económica de este patrimonio

6 Son reconocimiento de BIC por Ministerio de la LPHE "[...] las cuevas, abrigos rupestres y lugares que contengan manifestaciones de arte rupestre". (art .40.2 LPHE). $\mathrm{y}$, en definitiva, su conservación. Se intenta demostrar cómo esta complejidad administrativa profundiza en la brecha existente entre la población canaria y el disfrute del patrimonio arqueológico al mantener (bien por el coste y tiempo de los procedimientos administrativos, bien por la voluntad política), los bienes carentes de protección, y también sin posibilidades para su uso como recurso social y económico (Chávez y Pérez 2010; Arvelo, Pérez y Chávez 2017).

\section{El marco normativo para la gestión del patrimonio arqueológico en las Islas Canarias: muerte entre la abundancia}

Con este título, parafraseamos a Don Mitchell (2007), al referirse a los paisajes como sistemas de reproducción social, extrapolando su análisis al preguntarnos para qué sirve el marco normativo actual -abundante y complejoque afecta a la gestión del patrimonio arqueológico de las Islas Canarias, y cómo determina su implementación en la conservación y uso de los bienes arqueológicos.

En la Comunidad Autónoma de Canarias se efectuó la transferencia las competencias en materia de Cultura entre los años 1979 y 1984. Por Real Decreto 2843/1979 de 7 de diciembre, se realizaron las primeras transferencias en esta materia al ente preautonómico Junta de Canarias, tales como competencias, funciones y servicios de la Administración del Estado en lo que se refería al Centro Nacional de Lectura, Depósito Legal de Libros e ISBN, Tesoro Bibliográfico y Registro de la Propiedad Intelectual.

En el año 1982, y por la Ley Orgánica 10/1982, se aprobó el Estatuto de Autonomía de Canarias, y en la misma fecha, por Ley Orgánica 11/1982, continuó el traspaso de competencias, esta vez en materia de Juventud, Deportes y Promoción Sociocultural. Al año siguiente, con el Real Decreto 3355/1983, se traspasarían las funciones y servicios en materia de Bellas Artes, Patrimonio HistóricoArtístico, Música, Teatro, Cinematografía y Libro. Y, en 1984, se traspasaron los bienes, derechos y obligaciones, personal y créditos presupuestarios necesarios para adaptarse a la nueva situación configurada por el Estatuto de Autonomía. A partir de ese momento, Canarias asumió la gestión de su Patrimonio Cultural al amparo de la ley estatal y de los 
sucesivos decretos, reglamentos, órdenes y leyes que se fueron dictando, para más tarde ir transfiriendo parte de esas funciones a los Cabildos Insulares.

En el año 1988, por Decreto 60/1988, de 12 de abril del Gobierno de Canarias, se produce el traspaso de funciones y servicios de la Administración Pública de la Comunidad Autónoma de Canarias a los Cabildos Insulares en materia de cultura, deportes y patrimonio histórico, artístico e insular. En este Decreto se concretaron qué funciones y servicios tendrían en exclusiva cada una de estas Administraciones y en cuál concurrirían ambas. Para el caso del patrimonio histórico y en la materia que nos interesa, a partir de este Decreto, los cabildos insulares pasaban a autorizar y suspender en su caso, las obras a realizar en los BIC declarados o incoados, y a emitir el informe preceptivo y vinculante de los Planes Especiales de Protección (en adelante PEP), de las ZA (art. $\left.2^{\circ} .3 \mathrm{c}\right)$ y e))

El Gobierno de Canarias se quedaba así, con la función de autorizar y ordenar la ejecución de excavaciones y prospecciones arqueológicas (art. $\left.3^{\circ} .3 \mathrm{e}\right)$ ), y ambas administraciones compartían funciones en cuanto al procedimiento de declaraciones de los BIC, siendo los cabildos insulares los órganos competentes para incoar e instruir dichos procedimientos de aquellos bienes que no fueran de titularidad regional o estatal, y el Gobierno de Canarias el competente en su declaración y también en la inspección del patrimonio histórico (art. $\left.4^{\mathrm{o}} .3 . \mathrm{a}\right)$ ).

Tras la Ley 14/1990, de 26 de julio, de Régimen Jurídico de las Administraciones Públicas de Canarias, se hizo preciso revisar y completar el proceso de transferencias de competencias de los cabildos insulares que se inició en el año 1988, y se dictó un nuevo decreto, el Decreto 152/1994, de 21 de julio, de transferencias de funciones de la Administración Pública de la Comunidad Autónoma de Canarias de Canarias a los cabildos insulares en materia de cultura, deportes y patrimonio históricoartístico. Con este decreto se ampliaron y concretaron las funciones de esta administración insular con respecto la inclusión de la potestad sancionadora respecto de las funciones que tienen atribuidas y la inspección del patrimonio histórico insular (art. 2. 10) y 11)).

Como se puede observar son años donde se "estaba construyendo" una administración regional e insular nueva, con reparto y traspa- so de funciones y servicios, y que no supuso una fácil implementación de los procedimientos administrativos en general, reflejándose en los propios procedimientos de declaración de BIC, con, por ejemplo, incoaciones revocadas o caducadas, tal y como se evidencia en los expedientes consultados ${ }^{7}$.

Durante todo este proceso de transferencias de competencias y de funciones entre administraciones (regional, insular y local) se encuentra vigente la Ley 16/1985 de Patrimonio Histórico Español, en la cual se recoge la categoría de BIC de Zona Arqueológica, como aquel "lugar o paraje natural donde existen bienes muebles e inmuebles susceptibles de ser estudiados con metodología arqueológica, hayan sido o no extraídos y tanto si se encuentran en la superficie, en el subsuelo o bajo las aguas territoriales españolas", (art. 15.5 LPHE), así como el reconocimiento de BIC por Ministerio de esta Ley "[...] las cuevas, abrigos rupestres $y$ lugares que contengan manifestaciones de arte rupestre". (art. 40.2 LPHE). De esta manera queda conformado el doble origen de las declaraciones de los BIC arqueológicos, unas

\footnotetext{
Un ejemplo de ello es el caso del yacimiento arqueológico el Cenobio de Valerón, en la isla de Gran Canaria, declarado en 1978 monumento histórico artístico y arqueológico nacional (Real Decreto 2759/1978, de 14 de octubre (B.O.E. $\left.\mathrm{n}^{\circ} 282,25.11 .1978\right)$, cuya delimitación inicia el Gobierno de Canarias mediante Resolución de la Dirección General de Patrimonio Histórico el 27 de julio de 1992, cuatro años después de haber sido transferidas las competencias a los Cabildos. (B.O.C. nº116-19.08.1992). Hoy en día este yacimiento -incluido en la Red de Espacios Arqueológicos de Gran Canaria, visitables- no tiene delimitación. Otro ejemplo es el yacimiento arqueológico Barranco del Cavadero, declarado por ministerio de Ley, al ser un yacimiento con grabados aborígenes y uno de los conjuntos rupestres más importantes de Fuerteventura, cuya delimitación la incoa el Gobierno de Canarias mediante Resolución de la Dirección General de Patrimonio Histórico el 22 de mayo de 1992, cuatro años después de haber sido transferidas las competencias a los Cabildos (B.O.C. $\mathrm{n}^{\circ} 88-01.07 .1992$ ), y fue revocada por Resolución de la misma Dirección General de Patrimonio Histórico de fecha 14 de febrero de 1995. Un último ejemplo, entre otros, es la Zona arqueológica de La Candia en el municipio de Valverde, en la isla de El Hierro. Al ser una estación de grabados, estaba declarado por Ministerio de Ley de 1985, pero se incoó resolución de la Presidencia del Cabildo Insular de El Hierro el 21 de octubre de 1993 para su declaración (B.O.C. $\mathrm{n}^{\circ} 145$ - 15.11.1993), cuestión totalmente innecesaria. En el año 2000, se dicta Decreto 1925/2000 con resolución de 28 de septiembre de 2000, del Presidente de la Corporación Insular revocando la resolución de 1993 y delimitando la zona arqueológica (B.O.C. $\left.\mathrm{n}^{\circ} 151-17.11 .2000\right)$. Esta delimitación a día de hoy no ha sido aprobada y el procedimiento está de facto, caducado.
} 
tras procedimiento administrativo al efecto $\mathrm{y}$ otras por ministerio de ley, acorde a la LPHE.

\subsection{La Ley de Patrimonio Histórico de Canarias (1999)}

En 1999, en Canarias se aprueba la Ley 4/1999 de Patrimonio Histórico de Canarias (LPHC), una ley que, como la nacional, recoge entre sus categorías de BIC las Zonas Arqueológicas y también, como ella, recoge la posibilidad de la existencia de Zonas Arqueológicas que adquieran la máxima categoría de protección por ministerio de ley (art. 62.2 LPHC). Así, como la obligación de que, si la ZA se pueda ver afectada por obras o procesos urbanizadores, se deba redactar y aprobar un PEP para su ordenación (art. 59 LPHC). El problema que tiene esta ley, y que hereda la actual, es que al contrario de lo que se hace con los Conjuntos Históricos $(\mathrm{CH})$, en cuanto a las $\mathrm{ZA}$, no se incluye un contenido mínimo y específico para estos PEP (art. 31 LPHC Contenido básico de los PEP. de los $\mathrm{CH}$ ). Por lo que, como si ambas categorías fueran de igual naturaleza y necesitaran el mismo tratamiento, ese contenido queda remitido al de los $\mathrm{CH}$. Esta ley regional establecía (art. 62.3 LPHC), también, la obligación de evitar la degradación de los yacimientos declarados ZA y también, su acondicionamiento, en la medida de lo posible, como Parques Arqueológicos, para facilitar la visita pública de los mismos. Estas figuras, los parques arqueológicos, deberían ser aprobados por decreto del Gobierno de Canarias a propuesta de los Cabildos Insulares, previo expediente instruido al efecto y donde se incluya el informe favorable del Consejo Canario de Patrimonio Histórico (art. 63 LPHC), que es el máximo órgano consultivo y del conjunto de las Administraciones Públicas Canarias en las materias recogidas en la ley de 1999 y en la vigente (art. 11 LPHC y art. 18 LPCC).

En cuanto a la identificación del patrimonio arqueológico, la ley de 1999 establece la obligación de identificar, localizar e inventariar mediante cartas arqueológicas de ámbito municipal, los yacimientos de Canarias (art. 64 LPHC). Competencia que evidentemente es de índole municipal, y cuyo nivel de cumplimiento o de realización es de naturaleza variada. Existen ejemplos como el del municipio de Santa Cruz de Tenerife (Tenerife), con un patrimonio arqueológico que se puede identificar en dos de sus distritos (Anaga y el Suroeste), de reconocida importancia científica, pero en cuya carta arqueológica municipal sólo se han registrado 45 sitios arqueológicos, del todo un número escaso ante la realidad arqueológica existente ${ }^{8}$.

El resto de aspectos relacionados con el patrimonio arqueológico como la protección cautelar, e intervenciones, se recogieron en el resto del articulado así como en el Reglamento aprobado al efecto, donde se estableció que la competencia en esta materia la tiene el Departamento correspondiente del Gobierno de Canarias, a diferencia del resto de intervenciones en BIC cuya competencia la ostentan los $\mathrm{Ca}$ bildos Insulares (art. 2 del Decreto 262/2003, de 23 de septiembre, por el que se aprueba el Reglamento sobre intervenciones arqueológicas en la Comunidad Autónoma de Canarias y art. 3. a) y b) LPHC).

\subsection{La Ley de Patrimonio Cultural de Canarias (2019)}

El 12 de junio de 2019 se publicó en el Boletín Oficial de Canarias la Ley 11/2019, de 25 de abril, de Patrimonio Cultural de Canarias (LPCC). No es esta una modificación de la Ley de 1999, pues se planteó como un nuevo texto legislativo con una denominación más acorde con las nuevas corrientes que englobaban un patrimonio más amplio en su denominación, no sólo el histórico. Incluyó, entre otras novedades nuevas categorías de BIC y un nuevo instrumento de protección, una categoría intermedia entre la máxima protección que representan los BIC y los catálogos municipales: el catálogo insular. Esta nueva ley, en cuanto al patrimonio arqueológico, no incluyó grandes novedades, aunque sí es cierto que se modificó la definición de la categoría de Zona Arqueológica. Así, pasó de ser un lugar o paraje natural donde existen bienes muebles o inmuebles representativos de antiguas culturas (art. 18.1.e) LPHC), a un lugar donde existen bienes mue-

La Corporación Municipal está pendiente de licitar la redacción del inventario municipal del patrimonio arqueológico, en dos lotes, uno por cada distrito mencionado, debido al reconocido volumen de yacimientos existentes. Solo en la isla de Tenerife se han registrado un total de 27.836 datos de bienes arqueológicos, etnográficos y arquitectónico, estimando los arqueólogos que aún falta por censar el $50 \%$ de la riqueza patrimonial de la isla (La Vanguardia, 2019) Recuperado de: https://www.lavanguardia.com/local/canarias/20190207/46282219341/el-inventario-del-patrimonioen-tenerife-27000-datos-pero-falta-el-50.html [Fecha último acceso 02/08/2021]. 
bles e inmuebles de interés relevante para la Historia de Canarias, cuyo estudio y valoración requieran la aplicación de la metodología arqueológica (art. 23.e) LPCC). Se incorporó el uso de la metodología arqueológica como parte definitoria de esta categoría, aunque el texto legislativo cae en cierta incongruencia cuando al definir el patrimonio arqueológico, lo circunscribe a los bienes pertenecientes a las poblaciones aborígenes de Canarias cuyo estudio se realice por metodología arqueológica (art. 83 LPCC).

Según esta definición, lo registrado en las excavaciones que se realicen, por ejemplo, en el interior de una iglesia no sería denominado patrimonio arqueológico, aunque se le hubiera aplicado dicha metodología, una circunstancia que igualmente se vería aplicada en las recientes excavaciones de restos romanos en las islas. Esta incongruencia ha sido ya analizada previamente en la literatura científica (Querol y Martínez 1996; Castillo s/f;), y llama, sin embargo, la atención, el hecho de que los legisladores canarios vuelvan a incurrir en esta ambigüedad. Según este texto normativo un yacimiento romano no podría ser declarado BIC con la categoría de Zona Arqueológica, porque para ello tendría que formar parte de los bienes integrantes del patrimonio arqueológico, $\mathrm{y}$, por tanto, tener un origen aborigen (art. 87.1 LPCC).

Los BIC, en esta nueva norma, incluyen aquellos declarados por ministerio de ley (art. 87.2 LPCC), tanto los de naturaleza mueble como los inmuebles. Con la categoría de bien mueble, todas las colecciones de cerámica, incluidos idolos y pintaderas, pertenecientes a las poblaciones aborígenes de Canarias. Con especial referencia, debido a su naturaleza, a bienes muebles de especial sensibilidad, las momias, fardos, mortajas funerarias y restos antropológicos de las poblaciones aborígenes. Y con la categoría de zona arqueológica, todos los sitios, lugares, cuevas, abrigos o soportes que contengan manifestaciones rupestres y naturales de interés histórico. En este último caso es de destacar la inclusión a diferencia de la LPHC de manifestaciones de carácter natural e interés histórico que, interpretamos, como aquellos lugares utilizados como recursos, y por tanto con signos evidentes de explotación, por parte de las comunidades aborígenes.

Esta ley incorpora un nuevo instrumento de protección, el catálogo insular de bienes patrimoniales culturales, en el que deben ser incluidos aquellos bienes muebles o inmuebles que, sin tener los valores sobresalientes de los BIC, los cabildos insulares entiendan que deben ser especialmente preservados (art. 39 LPCC). Se incluyen dentro de los atributos a tener en cuenta los arqueológicos, con lo que se pone en manos de estas corporaciones locales un potente instrumento de reconocimiento y protección de los innumerables yacimientos arqueológicos que existen en las islas. Para inscribir bienes en este catálogo insular, se deberá seguir un procedimiento administrativo muy parecido al de las declaraciones de los BIC. Y en lo que respecta a su efecto, desde su incoación provocará su delimitación provisional, así como el de su entorno de protección; también se limitarán las obras y actuaciones mínimas que se necesiten realizar por fuerza mayor y se notificará a las personas interesadas y al Ayuntamiento donde se ubique el bien si es inmueble, así como a la Comunidad Autónoma de Canarias. Se dará plazo a información pública, se estudiará el bien y sus valores a tener en cuenta $y$, finalmente, tras informe favorable de la comisión insular de patrimonio cultural y por acuerdo del pleno del Cabildo Insular se incluirá el bien en el citado catálogo insular.

La LPCC 2019 incluye, además, una novedad importante, que afecta a las cartas municipales en general y, por tanto, también, a las arqueológicas, que es su desaparición. A partir de la entrada en vigor de esta ley, el patrimonio arqueológico que no sea reconocido como BIC o incluido en el catálogo insular y que sea de interés, estará incorporado en los catálogos municipales, que no serán ya sólo de naturaleza arquitectónica, sino en los que se incorporarán todos aquellos bienes o espacios que por sus valores históricos, artísticos, arquitectónicos, arqueológicos, etnográficos, bibliográficos, documentales, lingüísticos, paisajísticos, industriales, cientificos o técnicos, requieren de un régimen especifico de conservación [...] (art. 52.1 LPCC). En este sentido, en cuanto a las cartas existentes a fecha de la entrada en vigor de la ley, deberán incorporarse a algunos de los instrumentos de protección que recoge la ley (DT 9a LPCC).

Otro aspecto importante que va a influir en la gestión de las ZA es el cambio que se produce en cuanto a la obligación de redactar un PEP. En la LPHC de 1999, esta necesidad de ordenar el territorio donde se encontraba el yacimiento venía condicionado por el hecho de que se pudiera ver afectado por obras o proce- 
sos urbanizadores. Pero según la nueva ley en su artículo 87.3, se recoge que todas las zonas arqueológicas, requerirán de un PEP, tramitado y aprobado, conforme a la normativa urbanística, con informe previo preceptivo y vinculante del departamento del Gobierno de Canarias competente en materia de biodiversidad. Llama la atención, en este caso, la distinción que la norma realiza en cuanto a la redacción de los PEP de Conjuntos Históricos, pues en ellos, el informe que debe ser sólo favorable y cuyo silencio tras tres meses es de sentido positivo, es del cabildo insular, previo dictamen de la comisión insular de patrimonio cultural (art. 37.4 LPCC).

En la norma en cuanto a los PEP de las Zonas Arqueológicas se estipula la "obligatoriedad" de un informe del departamento de biodiversidad, que no del de patrimonio cultural del Gobierno regional, que es quien autoriza las intervenciones en los yacimientos, ni tampoco del departamento de patrimonio cultural del cabildo insular correspondiente. De esta forma se tiene en cuenta que, en la propia LPCC, no se recoge el contenido de ese PEP de Zonas Arqueológicas, sino que se traslada a un posterior desarrollo reglamentario (DT 9a). El legislativo en cuanto a la ordenación de este patrimonio tan sensible, sólo se ha preocupado de que no se apruebe ningún PEP sin el informe de un departamento que no se dedica al patrimonio cultural. Esta obligación puede retrasar la posibilidad de poner en marcha acciones de gestión actuales e integradoras (como pueden ser la creación de posibles parques arqueológicos), pero también la implantación de posibles acciones de participación ciudadana en estos procesos (Convenio de Faro 2005), que ayuden a comprender, difundir, educar, conservar y servir de recurso económico este patrimonio.

En este contexto estas posibilidades parecen quedar por tanto totalmente bloqueadas e inaccesibles para la gestión del patrimonio arqueológicos en las Islas Canarias.

\section{Los efectos de ser - o sufrir ser- BIC}

Cuando un yacimiento arqueológico es declarado BIC, como todo bien inmueble que logra esta máxima categoría, pasa a gozar de un régimen singular de protección y tutela, llevando incluso implícita la declaración de utilidad pública y de interés social a efectos de expropiación. Los propietarios o titulares de derechos reales de esos bienes, tienen un deber general de protección y conservación, limitaciones al libre disfrute y uso de los mismos, un plus de autorizaciones sumadas a las necesarias para cualquier intervención o actuación que quiera realizar en ellos e incluso el "peligro" de una posible expropiación.

La sistemática de declaraciones BIC en las Islas Canarias, si bien se ha amparado bajo la idea de conservar un legado cultural que forma parte de la identidad canaria y poder conservarlo para las generaciones futuras, muestra ciertas disfunciones. El análisis del número de BIC, de su distribución territorial o de su estado de conservación actual, así como de las acciones de divulgación de estos sitios arqueológicos, pone en entredicho la valoración positiva del proceso. De hecho, la política de declaraciones BIC no ha sido igualitaria ni territorialmente equitativa, siendo las islas capitalinas, Tenerife y Gran Canaria, las islas con más número de zonas arqueológicas protegidas con la categoría de BIC (Gráfico 1). Se ve, además, que la intención de las declaraciones, aumentaron bajo la incidencia de hitos administrativos específicos, como fueron la aprobación de la Ley de 1985 y la Ley de 1999 (Gráfico 2). Tal y como avanzó Pérez (2015), estos desequilibrios territoriales pueden deberse a varios motivos. Uno de ellos, puede deberse a que las instituciones académicas y las empresas de arqueología se encuentran ubicadas en las islas de Tenerife y Gran Canaria, cerca de las administraciones públicas con competencias en materia de patrimonio arqueológico (sectores de mayor incidencia en las intervenciones y gestión de este tipo de bienes).

Pero esta, y otras realidades, apuntan a que han sido los condicionantes políticos los que han determinado este hecho, unos condicionantes generados por las relaciones que se han ido estableciendo entre la Administración Autonómica y los Cabildos Insulares. Este hecho se consolidó en 1995 con el triunfo electoral de Coalición Canaria y fue determinante para fomentar la ya existente opción política que favorecía a los Cabildos con la transferencia de competencias. En palabras de Martín Ruíz, esta opción sería "más insularista y periférica en la Administración de la Comunidad, al potenciar la gestión y gobierno de los Cabildos Insulares (...) en cada uno de sus territorios e incluso en los ayuntamientos, propiciando la transferencia o delegación de ciertas competencias, previamente cedidas a la Comunidad 


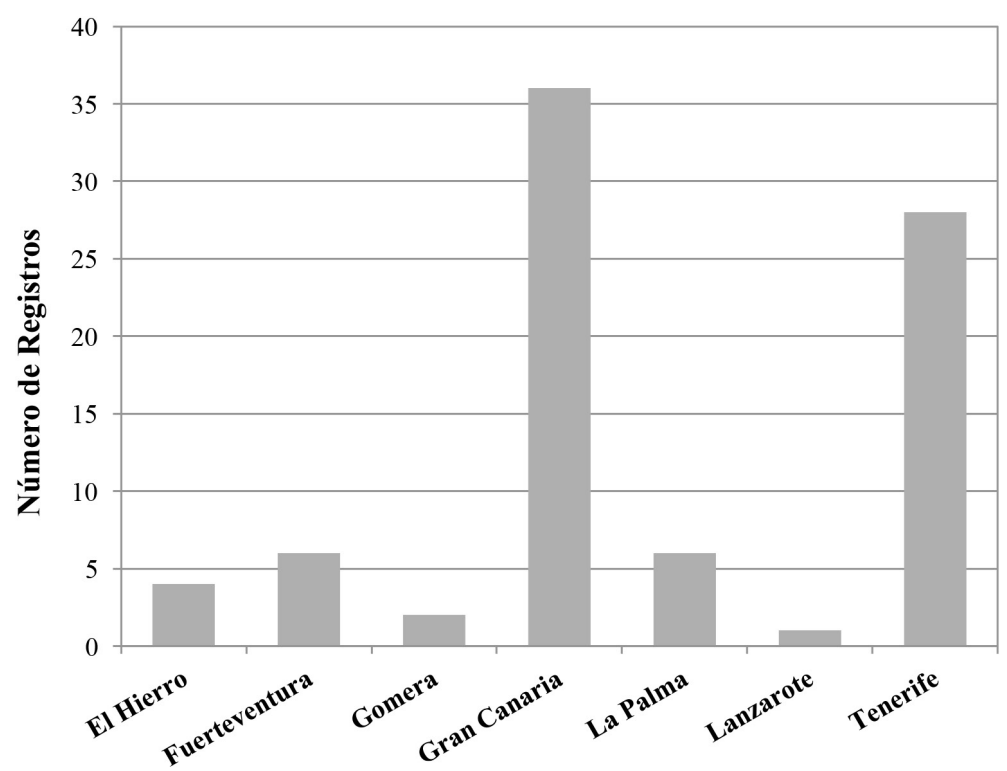

Isla

Gráfico 1. Número total de Zonas Arqueológicas en las Islas Canarias. Elaboración propia. Fuente: Dirección General de Patrimonio Cultural del Gobierno de Canarias.

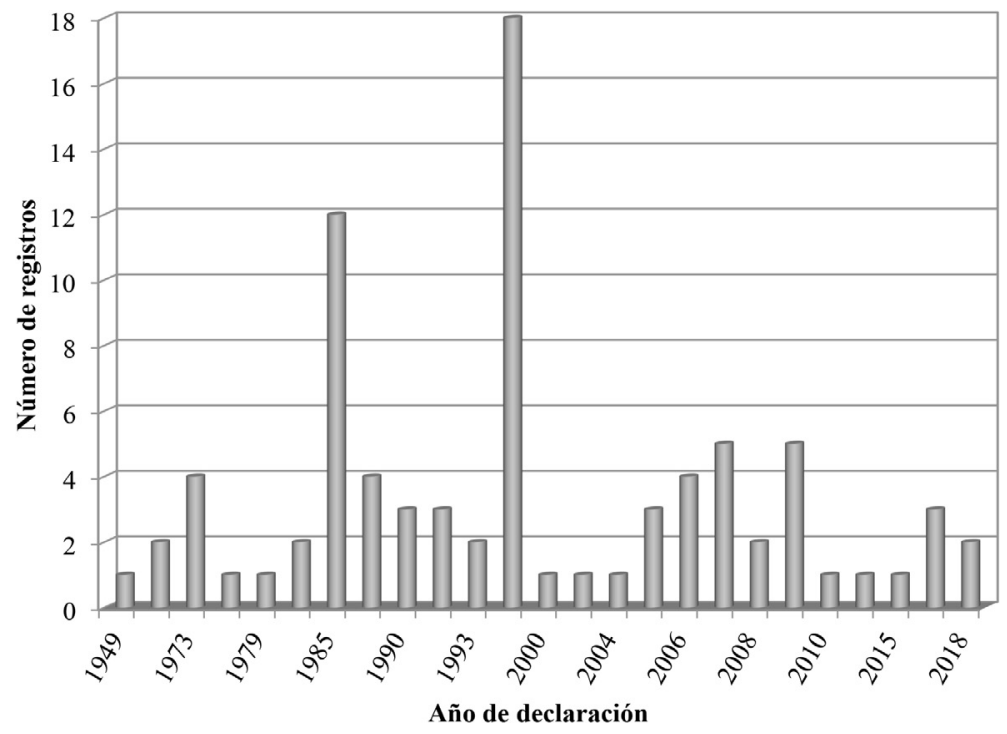

Gráfico 2. Número de Zonas Arqueológicas declaradas por año en las Islas Canarias. Elaboración propia.

Fuente: Dirección General de Patrimonio Cultural del Gobierno de Canarias.

Autónoma por el Estado" (Martín Ruíz 2001: 268-269). Según indica el mismo autor, la isla se convertiría en el marco de actuación económica, política y también de organización del territorio (por ejemplo, con los Planes Insulares del Territorio), y añade que bajo las crisis políticas de este partido subyace un debate que gira en torno a potenciar el Gobierno regional o los Gobiernos insularistas. Es decir, fomentar la planificación y gestión de una Administración Autonómica que tiene como marco de actuación el conjunto del archipiélago o, por el contrario, dar un mayor protagonismo a la isla y, en consecuencia, al Cabildo como su gobierno (Martín Ruíz 2001: 269-270). Así, se detecta cómo la dinámica de las autorizaciones es similar entre provincias, hasta mediados de los años 90 del siglo pasado y a partir de ese momento comienza a ser sustancialmente diferente (Pérez 2015).

Bien, toda declaración de un BIC de un bien inmueble debe llevar la delimitación y descrip- 
ción detallada del bien en sí y la delimitación de su entorno de protección o ámbito de respeto. En la ley nacional se establece que la declaración deberá describirlo claramente y delimitará el entorno afectado (art. 11.2 LPHE), circunstancia que se tendrá en cuenta desde la incoación del expediente de declaración (art. 12.2 RD 111/1986, de 10 de enero, de desarrollo parcial de la LPHE). La Ley Canaria de 1999, recoge en su articulado la referencia a la delimitación de los dos elementos a tener en cuenta en todo BIC, por un lado, el bien inmueble de interés cultural, en este caso el yacimiento, y por otro el de su entorno de protección (art. 26 LPHC). Sumando la definición de entorno de protección a los efectos de esa ley, como la zona periférica, exterior y continua al inmueble cuya delimitación se realiza a fin de prevenir, evitar o reducir un impacto negativo de obras, actividades o usos que repercutan en el bien a proteger, en su contemplación, estudio o apreciación de los valores del mismo. (art. 26.2 LPHC), dicho entorno que puede incluir el subsuelo, está constituido por el espacio, edificado o no, que da apoyo ambiental al bien y cuya alteración puede afectar a sus valores, a la contemplación o a su estudio (art. 15.1.b) del reglamento sobre procedimiento de declaración y régimen jurídico de los BIC).
La Ley actual, la de 2019, recoge igualmente la obligación en el caso de bienes inmuebles, de establecer desde el inicio del procedimiento de declaración de BIC la delimitación provisional, del bien y de su entorno de protección (art. 28 y 32 LPCC). También incluye la referencia a que se podrá omitir la publicación de los datos de localización del yacimiento que puedan ponerlo en peligro. Una circunstancia ésta de extrema gravedad que puede llegar a generar incluso la puesta en peligro de los sitios arqueológicos porque ante la realización de obras, los promotores no han conocido la localización de estos sitios. Todo esto hace que el conocimiento exacto de lo protegido o cuál es su delimitación y la de su entorno, sea esencial para la gestión del patrimonio arqueológico. La Tabla 1 muestra el estado administrativo actual de las zonas arqueológicas de Canarias y su conversión o no en un sitio accesible para la población y visitantes.

Uno de los ejemplos más paradigmáticos en este sentido es el yacimiento arqueológico de La Cueva del Tendal o Cuevas de San Juan, en el municipio de San Andrés y Sauces en la isla de La Palma. Dado el valor científico de este yacimiento para el conocimiento de la vida de los antiguos habitantes de esta isla, se concluyó la necesidad de su declara-

\begin{tabular}{|c|c|c|c|c|c|c|c|}
\hline \multirow[b]{2}{*}{ ISLA } & \multicolumn{7}{|c|}{ BIC CON CATEGORÍA DE ZONA ARQUEOLÓGICA } \\
\hline & REC & MIN & ERR & DEL & ENT & PEP & PEV \\
\hline TENERIFE & 28 & 14 & 3 & 25 & $11(\text { confuso })^{9}$ & 0 & 0 \\
\hline GRAN CANARIA & 36 & 5 & 2 & 32 ( 4 caducadas) & 9 & 3 & 7 \\
\hline LANZAROTE & 1 & 0 & 0 & (caducada) & 0 & 0 & 0 \\
\hline LA GOMERA & 2 & 0 & 0 & 2 & 0 & 0 & 0 \\
\hline EL HIERRO & 4 & 3 & 0 & 1 ( 3 caducadas $)$ & 0 & 0 & 2 \\
\hline FUERTEVENTURA & 6 & 3 & 1 & 5 & 5 & 1 & 1 \\
\hline \multirow[t]{2}{*}{ LA PALMA } & 5 & 5 & 0 & 2 ( 4 caducadas) & 0 & 0 & 3 \\
\hline & \multicolumn{7}{|c|}{$\begin{array}{l}\text { REC: Zonas arqueológicas reconocidas. MIN: Zonas arqueológicas por Ministerio de } \\
\text { Ley. ERR: Zonas arqueológicas declaradas por procedimiento administrativo pero que } \\
\text { lo son realmente por Ministerio de Ley. DEL: Delimitación- del BIC. ENT: con entorno } \\
\text { de protección. PEP: Plan Especial de Protección. PEV: Puesta en valor del yacimiento } \\
\text { arqueológico }\end{array}$} \\
\hline
\end{tabular}

Tabla 1. Estado administrativo actual de los Bienes de Interés Cultura con categoría de Zona Arqueológica. Elaboración propia. Fuente: Dirección General de Patrimonio Cultural de Canarias.

\footnotetext{
En la propia declaración, no queda claro si se está delimitando el entorno de protección o se está delimitando el BIC. No se aclara incluso con el aporte cartográfico y planimetría.
} 
ción de BIC y su puesta en valor por medio de un parque arqueológico. En enero de 1986, por resolución de la Dirección General de Cultura del Gobierno de Canarias se incoó expediente para su declaración como BIC (BOC $n^{\circ} 12$, 29.01.1986); en 1995, el Cabildo Insular, tras las transferencias de funciones en materia de patrimonio histórico, debido a una pequeña estación de grabados entiende que es ZA por Ministerio de Ley e incoa la delimitación del yacimiento (BOC $\left.\mathrm{n}^{\circ} 40,03.04 .1995\right)$, pero nunca se llega a declarar la delimitación de la ZA, aunque sí se realiza el parque arqueológico. La realidad es que ambas incoaciones se encuentran caducadas, la segunda de hecho y la primera con efectos del 11.01.1987, por Orden de la Consejería de Educación, Universidades, Cultura y Deportes de 11 de marzo, por la que se declara la caducidad de diversos expedientes de bien de interés cultural, (BOC $\mathrm{n}^{\mathrm{o}}$ 60, 26.03.2020). Por tanto, en el caso de La Palma concurre que hay un parque arqueológico, abierto y en funcionamiento con cuevas aborígenes y un yacimiento arqueológico cuya delimitación no ha sido declarada y con un decreto de creación inaccesible, ilocalizable o inexistente.

La administración pública canaria ha reconocido hasta ahora como BIC, 83 zonas arqueológicas a lo largo de las siete islas canarias. La realidad de este patrimonio en cada una de ellas ha sido muy diferente. Y todas han visto dificultada su gestión debido a la obligación de redactar el Plan Especial de Protección (PEP) para gestionar y ordenar las Zonas Arqueológicas (ZA), así como, la de necesitar obtener la aprobación de un decreto del Gobierno de Canarias, si se tuviese la intención de crear un parque arqueológico.

En particular, en Tenerife existen 28 zonas arqueológicas y sólo existe un proyecto de redacción de PEP en un BIC. En Gran Canaria, la isla con mayor número de ZA declaradas, encontramos, por el contrario, la existencia de diversos planes especiales de conservación y restauración, redactados antes de la aprobación de la ley de patrimonio histórico canario de 1999; esta isla, además, ha puesto accesibles 7 sitios arqueológicos a través de diferentes tipologías de interpretación. Lanzarote y la Gomera, con escasas ZA, no han redactado PEP de sus yacimientos, ni tampoco han creado Parques Arqueológicos. Fuerteventura con $6 \mathrm{ZA}$, sólo tiene un BIC, que tiene redactado también un plan especial de conservación previo a la aprobación de la ley de 1999 y la construcción de un centro de interpretación en ese lugar. La Palma y el Hierro son las islas que proporcionalmente han tenido más en cuenta sus ZA para difundir su patrimonio arqueológico aborigen. En La Palma, existen reconocidas $5 \mathrm{ZA}$, de las cuales 3 se han activado por medio de diferentes medios interpretativos; mientras que, en El Hierro, de sus 4 ZA, dos se han convertido en visitables.

\subsection{Entonces, ¿parques arqueológicos en las Islas Canarias?}

La difusión del patrimonio arqueológico, la puesta en valor de un yacimiento a través de un parque arqueológico supone la máxima expresión, si cabe, del éxito del procedimiento que se inicia con su declaración como BIC. Si bien existen otras modalidades de activación de estos sitios detectadas en Canarias ${ }^{10}$, solo los parques arqueológicos aparecen recogidos en la normativa. Tal y como se ha señalado, en la normativa autonómica canaria se recoge esta figura, siendo aquellos sitios y zonas donde se encuentran yacimientos arqueológicos que han sido declarados ZA previamente y que, procurando su integración con el entorno natural y territorial, se crean para fomentar el disfrute y facilitar la comprensión del citado lugar a los visitantes (art. 63 LPHC y art. 89 LPCC). Estos parques deben ser aprobados por Decreto del Gobierno de Canarias, a propuesta del Cabildo Insular correspondiente o a solicitud de sus propietarios y su creación debe estar acompañada de un proyecto donde se debe concretar, según la LPHC el régimen de uso, visitas, protección y demás condiciones que se establecieran reglamentariamente.

La LPCC del 2019 suma, además, la necesidad de incluir la financiación y el régimen de gestión, como garantía de que un proyecto de estas características pueda estar respaldado. Sin embargo, no se hace referencia a la función turístico-cultural-recreativa de estos parques arqueológicos. Por tanto, en los parques abiertos en las islas, ya mencionados, este tipo de consideraciones también se han obviado. Si bien no es objeto de estudio en este trabajo, lo cierto es que al ya duro camino para poder difundir y activar un yacimiento como parque

10 Centros de interpretación, centros de visitantes y parques culturales. 
arqueológico, se suma la indefinición del uso y gestión de estos lugares que, como mínimo, deberían atender a las siguientes características: ser un lugar con interés científico, histórico y educativo, un lugar conservado en su medio ambiente originario y cuya relación con el entorno fuera evidente, así como tener un proyecto museístico e infraestructura para su visita (Querol 1992-1993; Abad 2008, entre otros). Es importante también considerar que un parque arqueológico podría tener una intervención o proyecto arqueológico paralelo, y, por supuesto, acciones de consolidación y restauración de los vestigios. Por tanto, un parque arqueológico se entiende como un espacio dinámico y siempre con posibilidades de ofrecer cosas nuevas a los visitantes ya fueran locales o turistas. Su integración en los circuitos turísticos debería ser un factor para considerar, que podría ayudar a la economía de los sitios, y la consideración del patrimonio como un recurso para un desarrollo duradero. Existen islas donde han materializado estos conceptos con mayor o menor fortuna, como son Gran Canaria, El Hierro o La Palma y otras en las que, simplemente, a pesar de tener BIC con base suficiente para ello, no se han implantado.

Los yacimientos arqueológicos se configuran además como instrumentos educativos con alto grado de proyección social. La información que se difunde debe realizarse correctamente y debe llegar al mayor número posible de público. Del total de las 83 ZA en Canarias ${ }^{11}$, sólo hay 13 sitios accesibles para su visita, algunos autodenominados parques arqueológicos, parques culturales o centros de interpretación, dedicados a la difusión de este patrimonio de valores sobresalientes, y que no suponen más que el $16 \%$ de las declaraciones ZA.

\section{Conclusiones}

Tras analizar los expedientes de declaración como ZA de las Islas Canarias y su contexto normativo, se constata que han sido las administraciones quienes han generado un conjunto

11 Antes del año 1979, las ZA de Canarias eran sólo cuatro, todas ubicadas en la isla de Gran Canaria. En el momento del traspaso de funciones por el Decreto de 1988, el número de zonas arqueológicas había aumentado en once, distribuidas en el resto de las islas, excepto en la Gomera y Lanzarote, alcanzándose la cifra de 83 en la actualidad. de sitios arqueológicos protegidos pero inaccesibles para la población.

Ello se ha visto afectado, además, por la complejidad de la maquinaria normativa y burocrática que está impidiendo la fluidez de la aplicación de los instrumentos de protección y de puesta en valor. Esta situación ha estado favorecida por la transferencia de competencias desde el Gobierno a los Cabildos Insulares, así como por la aprobación de la Ley de Patrimonio Histórico de Canarias (1999) y más recientemente por la Ley de Patrimonio Cultural (2019). Unos hitos que, si bien han determinado una transformación -lenta- de la visión global y unificadora del conocimiento arqueológico, han determinado que las corporaciones insulares hayan adquirido cada vez más competencias en esta materia, implementando acciones de gestión específicas, particulares e independientes, según los objetivos trazados por cada uno de los cabildos insulares - un efecto que podemos ver en el número tan diverso y su distribución territorial, de declaraciones de BIC como ZA-.

Estas realidades que asumen las normativas autonómicas en el patrimonio arqueológico, las declaraciones por dos vías, procedimiento administrativo al efecto y otras por ministerio de ley, así como la necesidad de la redacción de un $\mathrm{PEP}^{12}$ para su ordenación, están siendo las causantes de los retrasos para abordar una ordenación y gestión de los sitios arqueológicos, lo que ha impedido que este tipo de patrimonio, en el caso de las Islas Canarias en particular, se haya incorporado como un activo para el desarrollo y crecimiento social y económico.

En el ámbito de la protección, no hay que olvidar que en Canarias existe un gran número de estaciones de grabados y de otros yacimientos que no han podido ser reconocidos por la administración hasta estos momentos por medio de una delimitación, o, aunque en los últimos años sí han querido realizar ese reconocimiento y protección por medio de la incoación de un expediente de BIC o delimitación, no han prosperado y esos expedientes han sido revocados o han caducado. Estaríamos hablando de 33 expedientes de declaración y 10 de delimitación, según la Orden de 11 de marzo de

2 En Canarias también pueden ser los cabildos insulares si el territorio afectado es plurimunicipal, de aprobar un PEP de una ZA $u$ otros instrumentos de planeamiento de los previstos en la legislación urbanistica que cumpla en todo caso las exigencias en esta Ley establecidas (art.20 LPHE). 
2020, por la que se declara la caducidad de diversos expedientes de bien de interés cultural de la Consejería de Educación, Universidades, Cultura y Deportes (BOC. n60, 2603.2020). En este proceso, también es necesario establecer los contenidos mínimos de los PEP de las ZA. La naturaleza de su reglamento establece que deban pasar por una consulta pública previa, lo que instaría la realización de un proceso activo de información y la posibilidad de que la ciudadanía participase en la gestión de estos bienes.

Por tanto, todo este patrimonio arqueológico relacionado con una declaración $\mathrm{BIC}$, tal y como se ha descrito, pero ¿cómo se gestiona ante esta complejidad administrativa? La figura de protección no es un problema. $\mathrm{Su}$ finalidad salvaguardar los valores sobresalientes del bien arqueológico. Pero la norma y el entramado de trabas burocráticas que se han establecido alrededor de este patrimonio, están contribuyendo a su deterioro y pérdida de valores (Chávez y Pérez 2010; Arvelo, Pérez y Chávez 2017).

En este contexto, quizás, de cara a la conservación y activación del patrimonio arqueológico, las administraciones públicas junto al resto de la sociedad canaria debería implementar acciones de corresponsabilidad integrando herramientas y espacios para conseguir que el patrimonio arqueológico en Canarias, puede tener un uso social y económico; así como reformular el procedimiento administrativo con otros canales más comunitarios y cercanos a la población, frente a la opinión y participación administrativa y experta, dominante hasta ahora. Debemos abogar, debido a la envergadura de este patrimonio y por la complejidad de su naturaleza para su conservación, la implicación de la ciudadanía, para una gestión más compartida, abierta y comunitaria a las poblaciones que son, en definitiva, quienes otorgan valor y significado al patrimonio arqueológico ${ }^{13}$. Llama la atención en el caso de Canarias, la ausencia absoluta de relaciones entre la ciudadanía y la gestión del patrimonio arqueológico, lo que contrasta con el ingente esfuerzo normativo que se ha

13 Desde el ámbito de la investigación, se ha llevado a cabo algunos estudios sobre la incorporación de la percepción de la ciudadanía como herramienta de gestión integral del patrimonio arqueológico que indican que se están llevando a cabo pasos en la participación social, pero aún sin normalizarse dentro de los canales de la administración pública (V.V.A.A., 2019; Pérez, López y Morales, 2021). llevado a cabo para regular su protección y gestión.

En la actualidad, no existen mecanismos participativos que se hayan implementado para activar una gestión más corresponsable y de mayor éxito en términos de conservación y difusión, estando, así, totalmente al margen de contextos internacionales como el determinado por el Convenio de Faro (2015), en el que se defienden este tipo de procesos.

El procedimiento y número de BIC existentes, paradójicamente, no ha significado una mejor conservación de los bienes arqueológicos. Esta situación es resultado de la política descentralizadora de competencias del Gobierno Autonómico a los Cabildos (Pérez 2015), lo que implica que los responsables de la tutela del patrimonio arqueológico no han valorado la importancia de la gestión del Patrimonio Arqueológico como elemento integrador y de equilibrio, sino que ha estado determinada por otros parámetros y variables como pueden ser la complejidad normativa o la inexistencia de un modelo de gestión planificado del patrimonio arqueológico, entre otras.

Dadas las características turísticas de la comunidad canaria, parece aconsejable aplicar una definición de parque arqueológico que incluya su uso turístico, de tal manera que puedan establecerse unos requisitos normativos y de calidad homogéneos para todos los sitios arqueológicos con esa capacidad de proyección social tan amplia como la que implica ser un parque arqueológico, así como se ha asumido su presupuesto y modelo de gestión. Por tanto, es necesario que se identifiquen las características reales y necesarias para la configuración de un parque arqueológico - criterios de puesta en valor-y que sean incluidos en la planificación turística del destino. Así como, la definición y requisitos para su creación del resto de centros o espacios dedicados a la difusión y gestión del patrimonio cultural en general y del arqueológico en particular.

Así, este estudio ha revelado que la conciencia y representación del patrimonio arqueológico en el desarrollo social y económico de Canarias apenas ha logrado avances en este sentido durante las políticas patrimoniales implementadas (Pérez 2015), ni bajo el amparo de la anterior ley de Patrimonio Histórico de Canarias (1999), durante su período de vigencia, ni por la Ley de Patrimonio Cultural de Canarias, de reciente aprobación (2019). 


\section{Bibliografía}

Abad, L. (2008): Parques arqueológicos y musealización de yacimientos. A distancia, 1: 98-103.

Arvelo, M., Pérez, E. M, Chávez-Álvarez, M. E. (2017): El patrimonio arqueológico del Barranco de Agua de Dios (Tegueste, Tenerife). ¿Un producto turístico? International Journal of Scientific Management and Tourism, 3 (1): 9-30.

Barroso Cruz, V. y Marrero Quevedo, C. (2005): Administración, arqueología y empresa. En: V Jornadas de Patrimonio Histórico: La arqueología canaria. Análisis de partida. Arrecife de Lanzarote el 16-18 de marzo de 2005. Lanzarote. (Inédito).

Canarias (1999). Plan de Desarrollo de Canarias 2000-2006 (PDCAN). Consejería de Economía y Hacienda. Gobierno de Canarias, Las Palmas de Gran Canarias.

Chávez Álvarez, M. E y Pérez González, E. M. (2010): La gestión e interpretación del patrimonio arqueológico: nuevos modelos para el desarrollo turístico en Canarias. Destinos turísticos maduros ante el cambio. Reflexiones desde Canarias (Raúl Hernández Martín, Agustín Santana Talavera, coord.), Instituto Universitario de Ciencias Políticas y Sociales, Universidad de La Laguna: 49-70.

Clavijo Redondo, M. A. y Navarro Mederos, J. F. (2004): El funambulismo ideológico de un arqueólogo en el periodo franquista. Tabona: Revista de Prehistoria y Arqueología, 13: 75-102.

Clavijo Redondo, M. A. y Navarro Mederos, J. F. (2005): La comisaría y delegación en las islas de El Hierro y La Gomera (1944-1970). Tabona: Revista de Prehistoria y Arqueología, 14: 149-194.

Del Arco Aguilar, M. C. y Farrujia de la Rosa, A. J. (2004): La arqueología en Canarias durante el Régimen franquista: el tema del primitivo poblamiento de las islas como paradigma (1939-1969). Trabajos de Prehistoria, 61 (1): 7-22.

Farrujia de la Rosa, A. J. (2006). Luis Diego Cuscoy y la arqueología oficial: el estudio del poblamiento prehistórico de Canarias. Tabona: Revista de Prehistoria y Arqueología, 15: 49-70.

Jiménez González, J. J. (1995): Una perspectiva histórica analítica del patrimonio arqueológico y etnoarqueológico canario. Eres (Arqueología), 5 (1): 23-31.

Jiménez González, J. J. (2005). Propuestas, acciones y balance de la Comisaría de patrimonio arqueológico y etnográfico de la primera Dirección General de Patrimonio Histórico del Gobierno de Canarias. $V$ Jornadas de Patrimonio Histórico: La arqueología canaria. Análisis de partida. Arrecife de Lanzarote el 16-18 de marzo de 2005. Lanzarote. (Inédito).

Martín Ruíz, J. F. (2001): Geografía de Canarias. Sociedad y medio natural. Cabildo de Gran Canaria, Las Palmas de Gran Canaria.

Martínez Díaz, B. y Querol Fernández, M. A. (2001): El tratamiento de los bienes arqueológicos en las leyes de patrimonio cultural e histórico de Cantabria, Baleares, Aragón, Canarias y Extremadura. Patrimonio Cultural y Derecho, 5: 11-64.

Mitchell, D. (2007): Muerte entre la abundancia: los paisajes como sistemas de reproducción social. La construcción social del paisaje (Joan Nogué i Font, coord.), Biblioteca Nueva, Madrid: 85-110.

Moreno Benítez, M.; Mendosa Medina, F.,; Suárez Medina, I.; Guillén Medina, J. (2005): Arqueólogos en el futuro: un futuro para los arqueólogos... ¡Por favor! V Jornadas de Patrimonio Histórico: La arqueología canaria. Análisis de partida. Arrecife de Lanzarote el 16-18 de marzo de 2005. Lanzarote. (Inédito).

Navarro Mederos, J. F.; Tejera Gaspar, A.; Cuenca Sanabria, J. (2005): 20 años después: la gestión del patrimonio arqueológico canario desde las transferencias a la Comunidad Autónoma. $V$ Jornadas de Patrimonio Histórico. La arqueología canaria un análisis de partida. (Inédito). Lanzarote.

Pérez Caamaño, F. y Soler Segura, J. (2005): Intervención arqueológica en el Lomo de Arico (Tenerife). Reflexiones en torno a la relación entre patrimonio, empresa y arqueología en Canarias. $V$ Jornadas de Patrimonio Histórico: La arqueología canaria. Análisis de partida. Arrecife de Lanzarote el 16-18 de marzo de 2005. Lanzarote. (Inédito).

Pérez González, E. (2014): Diagnosis y estrategias para una gestión del patrimonio arqueológico de las Islas Canarias. Servicio de Publicaciones de la Universidad de La Laguna, Universidad de La Laguna.

Pérez González, E.; Chávez Álvarez, M.E.; Camalich Massieu, M.D.; Martín Socas, D. (2015): Archaeological Heritage Management in the Canary Islands (Spain), and its relationship with tourism. Current trends in archaeological heritage preservation: National and International perspectives (S. Musteata; S. Caliniuc, ed.) BAR International series, Oxford: 73-76 
Pérez González, E.; López Arquillo, J. D.; Morales Casañas, D. (2020): Estado, uso y gestión de la torre defensiva de San Andrés (Santa Cruz de Tenerife). I Simposio anual de Patrimonio Natural y Cultural ICOMOS España. Universidad Politécnica de Valencia: 239-245.

Querol, M.A. (1992-1993). El parque arqueológico: definición y filosofía. Tabona, Revista de Prehistoria y Arqueología, VIII (1): 27-37.

Velasco Vázquez, J. y Rodríguez Santana, C. G. (2005): Investigación, arqueología y patrimonio: tres representaciones de una misma realidad. En: V Jornadas de Patrimonio Histórico: La arqueología canaria. Análisis de partida. Arrecife de Lanzarote el 16-18 de marzo de 2005. Lanzarote. (Inédito).

V.V.A.A. (2019): Percepción social y participación comunitaria como estrategias de gestión del paisaje cultural del Caserío de Masca (Buenavista del Norte, Tenerife). Cuaderniu, 7: 117-143

\section{Anexo normativo}

Convenio de Faro, 2005 Convenio Marco del Consejo de Europa sobre el valor del Patrimonio Cultural para la Sociedad.

Ley 16/1985, de 25 de junio de Patrimonio Histórico Español. (BOE nº 155 - 29.06.1985)

Ley 4/1999, de 15 de marzo, de Patrimonio Histórico de Canarias (BOC n 36 - 24.03.1999)

Ley 11/2019, de 25 de abril de Patrimonio Cultural de Canarias. (BOC n ${ }^{\circ} 90$ - 13.05.2019)

Decreto 262/2003, de 23 de septiembre, por el que se aprueba el Reglamento sobre intervenciones arqueológicas en la Comunidad Autónoma de Canarias. (BOC nº $194-06.10 .2003$ )

Decreto 111/2004, de 29 de julio, por el que se aprueba el Reglamento sobre Procedimiento de Declaración y Régimen Jurídico de los Bienes de Interés Cultural (BOC n $\left.{ }^{\circ} 157-13.08 .2004\right)$

Orden de la Consejería de Educación, Universidades, Cultura y Deportes de 11 de marzo, por la que se declara la caducidad de diversos expedientes de bien de interés cultural, (BOC n ${ }^{\circ} 60-26.03 .2020$ )

Ley Orgánica 10/1982, de 10 de agosto, de Estatuto de Autonomía de Canarias. (BOE nº 195 - 16.08.1982)

Ley Orgánica 11/1982, de 10 de agosto, de transferencias complementarias a Canarias. (BOE $\mathrm{n}^{\circ} 195-$ 16.08.1982)

Real Decreto 2843/1979, de 7 de diciembre, sobre transferencias de la Administración del Estado a la Junta de Canarias en materia de Actividades molestas, insalubres, nocivas, y peligrosas; Urbanismo; Agricultura; Turismo; Administración Local; Cultura y Sanidad. (BOE nº 307 - 24.12.1979)

Real Decreto 3355/1983, de 28 de diciembre, sobre traspaso de funciones y servicios del Estado a la Comunidad Autónoma de Canarias en materia de cultura. (BOE nº $23-27.01 .1984$ )

Real Decreto 301/1984, de 25 de enero, sobre valoración definitiva, ampliación de medios adscritos a los servicios traspasado y adaptación de los transferidos en fase preautonómica a la Comunidad Autónoma de Canarias en materia de cultura. (BOE n ${ }^{\circ} 41-17.02 .1984$ )

Decreto 60/1988, de 12 de abril, del Gobierno de Canarias, se produce el traspaso de funciones y servicios de la Administración Pública de la Comunidad Autónoma de Canarias a los Cabildos Insulares en materia de cultura, deportes y patrimonio histórico, artístico e insular (BOC $\left.{ }^{\circ} 71-06.06 .1988\right)$

Ley 14/1990, de 26 de julio, de Régimen Jurídico de las Administraciones Públicas de Canarias. (BOC n ${ }^{\circ}$ $96-01.08 .1990)$

Decreto 152/1994, de 21 de julio, de transferencias de funciones de la Administración Pública de la Comunidad Autónoma de Canarias de Canarias a los Cabildos Insulares en materia de cultura, deportes y patrimonio histórico-artístico. (BOC n $\left.{ }^{\circ} 092-28.07 .1994\right)$ 
